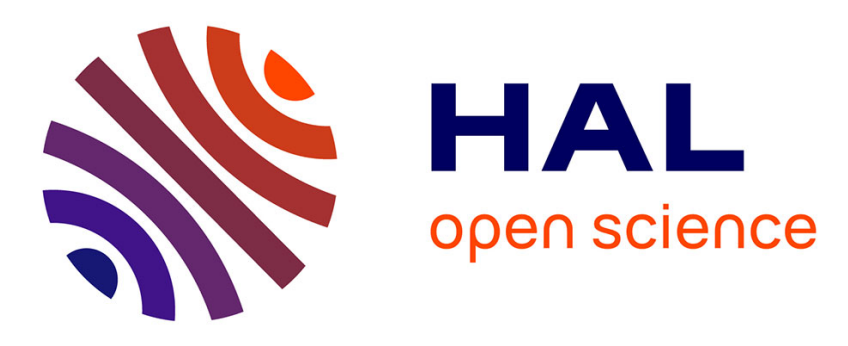

\title{
Furanolysis with Menthofuran: A New Depolymerization Method for Analyzing Condensed Tannins
}

Guillaume Billerach, Laurent Roumeas, Eric Dubreucq, Hélène Fulcrand

\section{- To cite this version:}

Guillaume Billerach, Laurent Roumeas, Eric Dubreucq, Hélène Fulcrand. Furanolysis with Menthofuran: A New Depolymerization Method for Analyzing Condensed Tannins. Journal of Agricultural and Food Chemistry, 2020, 68 (10), pp.2917-2926. 10.1021/acs.jafc.9b00497 . hal-02295527

\section{HAL Id: hal-02295527 \\ https://hal.science/hal-02295527}

Submitted on 24 Sep 2019

HAL is a multi-disciplinary open access archive for the deposit and dissemination of scientific research documents, whether they are published or not. The documents may come from teaching and research institutions in France or abroad, or from public or private research centers.
L'archive ouverte pluridisciplinaire HAL, est destinée au dépôt et à la diffusion de documents scientifiques de niveau recherche, publiés ou non, émanant des établissements d'enseignement et de recherche français ou étrangers, des laboratoires publics ou privés. 


\section{Furanolysis with menthofuran: A new depolymerization method}

for analyzing condensed tannins

Guillaume Billerach, ${ }^{\dagger \ddagger}$ Laurent Rouméas, ${ }^{\ddagger}$ Eric Dubreucq, ${ }^{\ddagger}$ and Hélène Fulcrand ${ }^{*,+\ddagger}$

+ INRA, Montpellier SupAgro, UMR 1083 SPO Sciences pour I'CEnologie, 2 Place Viala, 34060 Montpellier, France

₹ INRA, Montpellier SupAgro, UMR 1208 IATE Ingénierie des Agropolymères et Technologies Emergentes, 2 Place Viala, 34060 Montpellier, France

*E-mail : helene.fulcrand@inra.fr

ORCID

Guillaume Billerach: 0000-0001-6056-8958

Eric Dubreucq: 0000-0002-8904-504X

Hélène Fulcrand: 0000-0002-6035-1457

Laurent Rouméas: 0000-0002-6645-7471 


\section{$1 \quad$ ABSTRACT}

2 An improved analytical depolymerization method for characterizing condensed tannins was

3 developed with menthofuran (3,6-dimethyl-4,5,6,7-tetrahydro-1-benzofuran) as the

4 nucleophilic trapping reagent. Herein, menthofuran was compared with routinely used

5 nucleophiles, phloroglucinol and 2-mercaptoethanol. At $30^{\circ} \mathrm{C}$ and in the presence of $0.1 \mathrm{M}$

$6 \mathrm{HCl}$, menthofuran displayed the outstanding ability to enable the fast and full

7 depolymerization of procyanidin B2 using only a 1:1 molar ratio of both reactants. In the same

8 conditions, phloroglucinol and 2-mercaptoethanol led to a reaction equilibrium with

9 significantly lower conversion yields. Application to commercial tannin extracts showed that

a menthofuran to extract weight ratio of 1 gave the same yields of procyanidin constitutive

11 units as 10-fold higher mol. eq. phloroglucinol and 100-fold 2-mercaptoethanol. Finally,

12 guidelines for implementing the menthofuran depolymerization method are proposed to assess the tannin content and composition of extracts as well as of plant materials without 14 prior extraction.

\section{KEYWORDS}

17 Menthofuran, Furan derivatives, Condensed tannins, Depolymerization, Analytical method,

Furylated flavonoids, UHPLC-DAD-MS 


\section{INTRODUCTION}

Condensed tannins (proanthocyanidins) are polymers of flavan-3-ol units. The constitutive units are covalently linked by interflavan bonds between the phloroglucinol ring (C8 and/or C6 carbon atoms) and the benzylic C4 carbon atom of the extension units, thus resulting in Btype proanthocyanidins (Scheme 1 for carbon numbering). ${ }^{1,2}$ Additional linkages resulting from oxidation processes can lead to A-type proanthocyanidins, or biaryl and biaryl ether linked compounds. ${ }^{2}$ Condensed tannins, along with hydrolyzable tannins and phlorotannins, constitute the polyphenolic secondary metabolite class of tannins. ${ }^{3}$ These plant polyphenols represent the fourth most abundant organic polymer in the terrestrial biomass and the second one, after lignin, when considering only aromatic polymers. ${ }^{4,5}$

The need to characterize and quantify the condensed tannin fraction from plant or food samples generally meets three objectives. First, characterization of condensed tannins can be used in taxonomy or structure-function relationship studies, ${ }^{6}$ including response to environmental stresses. ${ }^{7,8}$ The second objective is to qualify plant extracts or tannin-rich formulations eventually intended for commercial products, such as cosmetics and dietary supplements, in relation to health benefits including antioxidant activities. ${ }^{9-11}$ The third motivation is to develop specialty chemicals or polymer materials from renewable phenolics accordingly to the properties and specificities of the different types of tannins. ${ }^{12-14}$ Non-degradative and degradative methods have been developed to characterize the condensed tannin fraction of plant materials. Among the former, colorimetric assays based on redox reactions are not specific to polyphenols and tannins and should be interpreted with caution. ${ }^{15}$ Methods based on ${ }^{1} \mathrm{H} \mathrm{NMR}{ }^{16}$ and ${ }^{13} \mathrm{C} \mathrm{NMR},{ }^{17} 2 \mathrm{D}{ }^{1} \mathrm{H}-{ }^{13} \mathrm{C} \mathrm{HSQC} \mathrm{NMR}{ }^{18}$ spectroscopy, as well as on mass spectrometry with electrospray ionization ${ }^{19}$ and MALDI-TOF systems, ${ }^{20}$ have been developed with the advances of technologies. These methods provide good 
information on the nature of constitutive units, types of linkages and degrees of polymerization of tannin structures. The limitations of these methods mainly result from the dispersity of tannin polymers associated with a possible discrimination against highly polymerized structures. ${ }^{21}$

On the other hand, degradative methods are based on a chemical depolymerization reaction leading to the release of two kinds of constitutive units: the terminal units, with free $\mathrm{C} 4$ carbon atom, and the extension units, where the $\mathrm{C} 4$ position is linked to the next unit of the polymeric chains (Scheme 1). The depolymerization products can then be analyzed by chromatography to infer characteristics of the initial tannin structures, including the type and amounts of constitutive units, mean degree of polymerization and galloylation degree. Depolymerizationbased methods are currently the most informative methods to characterize condensed tannins. They have recently been shown to give results consistent with NMR and MALDI analyses. ${ }^{22}$ Recent developments based on proanthocyanidin in-source fragmentation and mass spectrometry analysis also gave similar results in terms of composition and mean degree of polymerization of oligomeric and polymeric tannin fractions as chemical depolymerization. ${ }^{23}$ However, some information remains inaccessible to depolymerizationbased methods, such as the molecular weight distribution of the tannin fractions or the sequences of constitutive units in the polymeric chains beyond hexamers, owing to their too low content in the samples. ${ }^{24}$ Moreover, some linkages are much more stable with respect to cleavage, such as interflavan linkages of 5-deoxy condensed tannins found in quebracho and acacia, ${ }^{25}$ while others are totally resistant, like the A-type patterns ${ }^{26}$ and biaryl or biaryl ether linkages resulting from oxidation. ${ }^{27}$

Since the first report by Betts et al., ${ }^{28}$ different depolymerization-based methods have been developed, ${ }^{29-31}$ compared, ${ }^{4,32}$ and applied to characterize the condensed tannin fraction in 
plant extracts or food samples. ${ }^{21,33,34}$ Updates and improvements of these methods are still regularly published. ${ }^{35-37}$ The first nucleophiles used to trap the extension units released by the acid-catalyzed depolymerization of condensed tannins were mercaptans, such as thioglycolic acid and benzylmercaptan. 22,28,34,38 Later works proposed to substitute mercaptans by analogs of the catechin A-ring (e.g., phloroglucinol, 2,4,6-trihydroxytoluene or resorcinol). ${ }^{30,39}$ Ever since, these methods have evolved with analytical techniques and useful optimizations were performed on reaction conditions, solvents and work-up, but no significant breakthrough was achieved regarding the reactants. Indeed, the typical smell of mercaptans has often been an obstacle to their use in the analysis of condensed tannins. ${ }^{30}$ The toxicity of the chemicals involved in the depolymerization methods is more generally questioned, owing to the fact that the trapping nucleophiles are used in large excess. This especially concerns mercaptans frequently used in the analysis of proanthocyanidins, ${ }^{40,41}$ while phloroglucinol seems to require higher doses to cause adverse effects. ${ }^{42}$

Recently, the possibility to use metalloles (five-membered heterocyclic aromatic compounds) in the depolymerization of condensed tannins to produce biobased chiral ligands or fully biobased aromatic building blocks for applications in specialty chemicals and materials was evidenced by Fu et al. ${ }^{43}$ with pyrrole derivatives and by Rouméas et al. ${ }^{44,45}$ with furan derivatives. In the framework of our studies on the depolymerization of condensed tannins in the presence of substituted metalloles, preliminary experiments have led us to identify menthofuran (3,6-dimethyl-4,5,6,7-tetrahydro-1-benzofuran), a tri-substituted furan, as both an efficient and commercially available nucleophilic trapping reagent. Menthofuran, a major component of essential oils such as pennyroyal oil, has been the subject of numerous toxicological studies. ${ }^{46,47}$ It is used as a flavoring agent (strong peppermint odor) in the food industry at a concentration up to $1000 \mathrm{ppm}$ (i.e., in the same order of magnitude as in the 
method described herein). ${ }^{48,49}$ This led us to evaluate it as a potential new reagent for the analytic depolymerization of condensed tannins. In the present work, menthofuran was compared to phloroglucinol and 2-mercaptoethanol, that are routinely used in standard depolymerization methods. ${ }^{30,31}$

\section{MATERIAL AND METHODS}

\section{Chemicals}

The grape seed extract was purchased from Union des Distilleries de la Méditerranée (UDM, France). Pycnogenol, a commercial tannin bark extract from maritime pine (Pinus pinaster Aiton subsp. atlantica syn. P. maritima), was kindly offered by Horphag Research (Geneva, Switzerland). Samples of grape pericarp powder (Vitis vinifera L. subsp. sativa (DC.) Hegi, cultivar Savagnin), prepared as previously published ${ }^{50}$ were kindly supplied by Dr. Charles Romieu. Bark from Douglas fir (Pseudotsuga menziesii), kindly provided by Brassac Industrie sawmill (Brassac, France), was obtained from trees felled in March 2015 on a plot located at $43^{\circ} 33^{\prime} 39.5^{\prime \prime} \mathrm{N}, 2^{\circ} 42^{\prime} 14.0^{\prime \prime} \mathrm{E}$ (altitude $936 \mathrm{~m}$ ) and debarked in April 2015 under batch reference "chantier Caraman n'UG 47109". The bark was ground by knife milling using a Retsch SM 100 system operating at room temperature at a speed of $1500 \mathrm{rpm}$ with a $2 \mathrm{~mm}$ size screen. Menthofuran (3,6-dimethyl-4,5,6,7-tetrahydro-1-benzofuran, $\geq 95 \%$ ) and 2 mercaptoethanol (>99\%) were purchased from Sigma-Aldrich (France). Phloroglucinol (>99\%) was purchased from Merck (France). Procyanidin B2 ( $\geq 90 \%),(-)$-epicatechin ( $\geq 99 \%),(+)$ catechin ( $\geq 99 \%)$, (-)-epicatechin-3-O-gallate ( $\geq 97.5 \%),(-)$-epigallocatechin ( $\geq 98 \%)$ and (-)-epigallocatechin-3-O-gallate ( $\geq 98 \%)$ were purchased from Extrasynthese (France). 


\section{Depolymerization experiments}

All depolymerization experiments described in the following sections were performed in three independent replicates.

Depolymerization of procyanidin B2 with 1 molar equivalent of nucleophile. Owing to the purity of the commercial B2 sample ( $\geq 90 \%)$, a B2 solution was first prepared with approximate concentration. After determination of the concentration by measuring the peak area at $280 \mathrm{~nm}$ with the UHPLC-DAD-MS system, the B2 solution was then precisely adjusted to 1.05 $\mathrm{mM}$ by addition of methanol. For each depolymerization kinetics, equal volumes of methanolic solutions of procyanidin B2 $(1.05 \mathrm{mM})$, nucleophile $(1.05 \mathrm{mM})$ and hydrochloric acid $(\mathrm{HCl}, 0.3 \mathrm{M})$ were mixed and distributed in 8 vials, which were immediately sealed and incubated at $30^{\circ} \mathrm{C}$. Vials were withdrawn at different times and directly analyzed by UHPLCDAD-MS.

Depolymerization of procyanidins from a grape seed extract with optimized amounts of nucleophiles. Methanolic solutions of phloroglucinol (30 g. $\left.\mathrm{L}^{-1} ; 0.24 \mathrm{M}\right), 2$-mercaptoethanol (165 $\mathrm{g} \cdot \mathrm{L}^{-1} ; 2.1 \mathrm{M}$, prepared as a $15: 85 \mathrm{v} / \mathrm{v}$ 2-mercaptoethanol/methanol mixture) and menthofuran $\left(3 \mathrm{~g} \cdot \mathrm{L}^{-1} ; 0.020 \mathrm{M}\right.$ ) were prepared. For each depolymerization kinetics, equal volumes of methanolic solutions of grape seed extract $\left(3 \mathrm{~g} \cdot \mathrm{L}^{-1}\right)$, nucleophile and $\mathrm{HCl}(0.3 \mathrm{M})$ were mixed and distributed in 10 vials, which were immediately sealed and incubated at $30^{\circ} \mathrm{C}$. Vials were withdrawn at different times and directly analyzed by UHPLC-DAD-MS.

Characterization of pycnogenol with the menthofuran method. For each depolymerization kinetics, equal volumes of methanolic solutions of pycnogenol $\left(3 \mathrm{~g} \cdot \mathrm{L}^{-1}\right)$, menthofuran $\left(3 \mathrm{~g} \cdot \mathrm{L}^{-1}\right.$; $0.020 \mathrm{M})$ and $\mathrm{HCl}(0.3 \mathrm{M})$ were mixed and distributed in 3 vials, one for each reaction time, which were immediately sealed and incubated at $30^{\circ} \mathrm{C}$. Vials were withdrawn after 90,120 and 150 min and directly analyzed by UHPLC-DAD-MS. 

the protocol proposed by Kennedy and Jones. ${ }^{30}$ Methanolic solutions of pycnogenol (15 g. $\left.\mathrm{L}^{-1}\right)$, ascorbic acid (30 $\left.\mathrm{g} \cdot \mathrm{L}^{-1} ; 0.39 \mathrm{M}\right)$ and $\mathrm{HCl}(0.3 \mathrm{M})$ were prepared. For each depolymerization experiment, the pycnogenol solution was used to solubilize phloroglucinol (150 g.L-1; $1.2 \mathrm{M}$ ). Immediately after, equal volumes of ascorbic acid, $\mathrm{HCl}$ and pycnogenol/phloroglucinol solutions were mixed and the depolymerization solution was incubated at $50^{\circ} \mathrm{C}$ in a closed flask. The final pycnogenol concentration was thus $5 \mathrm{~g} \cdot \mathrm{L}^{-1}$. At $20 \mathrm{~min}$ of reaction time, the depolymerization solution was mixed with five volumes of an aqueous solution of sodium acetate $(40 \mathrm{mM})$. The final solution was directly analyzed by UHPLC-DAD-MS.

Characterization of grape pericarp powder with the menthofuran method. A sample of grape pericarp powder $(18 \mathrm{mg}$ ) was suspended in $0.6 \mathrm{~mL}$ of methanol in a closed flask. Then, methanolic solutions of menthofuran $\left(0.6 \mathrm{~mL} ; 30 \mathrm{~g} \cdot \mathrm{L}^{-1} ; 0.24 \mathrm{M}\right)$ and $\mathrm{HCl}(0.6 \mathrm{~mL} ; 0.3 \mathrm{M})$ were added. The closed flask containing the depolymerization solution was incubated at $30^{\circ} \mathrm{C}$. At $2 \mathrm{~h}$ of reaction time, a sample was withdrawn, centrifuged $1 \mathrm{~min}$ at $3000 \times \mathrm{g}$, filtrated and directly analyzed by UHPLC-DAD-MS.

Characterization of grape pericarp powder with the 2-mercaptoethanol method. The analysis was based on the protocol proposed by Tanaka et al. ${ }^{31} \mathrm{~A}$ sample of grape pericarp powder $(18 \mathrm{mg}$ ) was suspended in $0.6 \mathrm{~mL}$ of methanol in a closed flask. Then, methanolic solutions of 2-mercaptoethanol (0.6 mL; 165 g.L-1; $2.1 \mathrm{M})$ and $\mathrm{HCl}(0.6 \mathrm{~mL} ; 0.3 \mathrm{M})$ were added. The closed flask containing the depolymerization solution was incubated at $40^{\circ} \mathrm{C}$. At $2 \mathrm{~h}$ of reaction time, a sample was withdrawn, centrifuged $1 \mathrm{~min}$ at $3000 \times \mathrm{g}$, filtrated and directly analyzed by UHPLC-DAD-MS. 
$\left(10 \mathrm{~g} \cdot \mathrm{L}^{-1}\right)$. Then, menthofuran $\left(94 \mu \mathrm{L}\right.$; final concentration $\left.2 \mathrm{~g} \cdot \mathrm{L}^{-1} ; 0.013 \mathrm{M}\right)$ and $\mathrm{HCl}(417 \mu \mathrm{L}$; final concentration $0.1 \mathrm{M}$ ) were added and the depolymerization medium was incubated at $30^{\circ} \mathrm{C}$. At defined time intervals, a sample was withdrawn, centrifuged $1 \mathrm{~min}$ at $3000 \times \mathrm{g}$, filtrated and directly analyzed by UHPLC-DAD-MS.

\section{Characterization of the procyanidins from Douglas fir barks with the 2-mercaptoethanol}

method. Douglas fir barks ground and sieved at $2 \mathrm{~mm}(500 \mathrm{mg}$ ) were suspended in $47 \mathrm{~mL}$ methanol. Then, 2-mercaptoethanol (2.5 mL; final concentration 5:95 v/v) and $\mathrm{HCl}(417 \mu \mathrm{L}$; final concentration $0.1 \mathrm{M}$ ) were added and the depolymerization mixture obtained was incubated at $40^{\circ} \mathrm{C}$. At defined time intervals, a sample was withdrawn, centrifuged $1 \mathrm{~min}$ at $3000 \times g$, filtrated and directly analyzed by UHPLC-DAD-MS.

\section{Preparation, isolation and characterization of epicatechin-menthofuran (EC-MF)}

The grape seed extract ( $20 \mathrm{~g})$ was dissolved in methanol $(280 \mathrm{~mL})$. Menthofuran $(21.0 \mathrm{~mL}$; $0.136 \mathrm{~mol})$ and $\mathrm{HCl}(4.17 \mathrm{~mL}$ of $37 \% \mathrm{HCl}$ in $200 \mathrm{~mL}$ methanol) were added. The reaction was performed for $1 \mathrm{~h}$ at $30^{\circ} \mathrm{C}$ under magnetic stirring. The medium was then neutralized with a solution of sodium hydrogenocarbonate $(4.2 \mathrm{~g})$ in water $(700 \mathrm{~mL})$. Methanol was evaporated under vacuum. The remaining aqueous phase was extracted with ethyl acetate ( 3 times 500 $\mathrm{mL}$ ). The organic layers were gathered, dried with sodium sulfate, filtrated and evaporated under vacuum. The dark powder obtained $(27 \mathrm{~g})$ was triturated and sonicated for $5 \mathrm{~min}$ in diethyl ether ( 3 times $300 \mathrm{~mL}$ ). The diethyl ether fractions were pooled, dried with sodium sulfate, filtrated and evaporated under vacuum. Remaining traces of menthofuran were eliminated by trituration in petroleum ether ( 3 times $100 \mathrm{~mL}$ ). A purple powder was obtained (21 g) containing C, EC, ECG, C-MF, EC-MF and ECG-MF (see the abbreviation section and Scheme 1). A sample (1 g) was purified by flash chromatography on a PF430 system (Interchim, France) equipped with a silica gel column ( $120 \mathrm{~g}$; granulometry $63-200 \mu \mathrm{m})$. The flow rate was 
set to $40 \mathrm{~mL} \cdot \mathrm{min}^{-1}$ and the gradient was: solvent $A\left(\mathrm{CH}_{2} \mathrm{CL}_{2}\right)$, solvent $B\left(\mathrm{CH}_{2} \mathrm{Cl}_{2}-\mathrm{CH}_{3} \mathrm{OH}, 90: 10\right.$, v/v); 0-2 min, 0\% B (isocratic); 2-15 min, 0\% to 50\% B (linear gradient); 15-28 min, 50\%-80\% B (linear gradient); and 28-45 min, 80\% B (isocratic). Fractions were analyzed by UHPLC-DADMS before being combined and evaporated under vacuum to yield a pale purple pulverulent solid (80 mg) containing EC-MF (> $90 \%$ purity according to UHPLC analyses). For NMR characterization, EC-MF was dissolved in d6-DMSO.

1D and 2D NMR spectra acquisitions were performed at $25^{\circ} \mathrm{C}$ with an Avance III HD NMR spectrometer (Bruker, Germany) at $500 \mathrm{MHz}$ for ${ }^{1} \mathrm{H}$ and $126 \mathrm{MHz}$ for ${ }^{13} \mathrm{C}$. HRMS spectrum was acquired on a MicroTof QII mass spectrometer (Bruker) using the TOF MS ES+ mode, with samples dissolved in $\mathrm{MeOH}$. Spectra are provided as supporting information (Figures S1 to S5). Epicatechin-(4 $\rightarrow 5)$-menthofuran. ${ }^{1} \mathrm{H}$ NMR $\delta(\mathrm{ppm}): 9.12\left(1 \mathrm{H}, \mathrm{s}, \mathrm{H}_{10}\right), 9.04\left(1 \mathrm{H}, \mathrm{s}, \mathrm{H}_{11}\right), 8.89(1 \mathrm{H}$, s, $\left.\mathrm{H}_{8^{\prime}}\right), 8.77\left(1 \mathrm{H}, \mathrm{s}, \mathrm{H}_{7^{\prime}}\right), 6.85\left(1 \mathrm{H}, \mathrm{s}, \mathrm{H}_{2^{\prime}}\right), 6.68\left(1 \mathrm{H}, \mathrm{d}, J=8.3 \mathrm{~Hz}, \mathrm{H}_{5^{\prime}}\right), 6.58\left(1 \mathrm{H}, \mathrm{d}, J=8.3 \mathrm{~Hz}, \mathrm{H}_{6^{\prime}}\right)$, $5.87\left(1 \mathrm{H}, \mathrm{s}, \mathrm{H}_{8}\right), 5.78\left(1 \mathrm{H}, \mathrm{s}, \mathrm{H}_{6}\right), 5.05\left(1 \mathrm{H}, \mathrm{bs}, \mathrm{H}_{9}\right), 4.77\left(1 \mathrm{H}, \mathrm{s}, \mathrm{H}_{2}\right), 4.05\left(1 \mathrm{H}, \mathrm{s}, \mathrm{H}_{4}\right), 3.78(1 \mathrm{H}, \mathrm{bs}$, $\left.H_{3}\right), 2.56\left(1 \mathrm{H}, m, H_{7^{\prime \prime}}\right), 2.27\left(2 \mathrm{H}, \mathrm{m}, \mathrm{H}_{4^{\prime \prime}}\right), 2.10\left(1 \mathrm{H}, \mathrm{m}, \mathrm{H}_{7^{\prime \prime}}\right), 1.84\left(1 \mathrm{H}, \mathrm{m}, \mathrm{H}_{6^{\prime \prime}}\right), 1.77\left(1 \mathrm{H}, \mathrm{m}, \mathrm{H}_{5^{\prime \prime}}\right)$, $1.67\left(3 \mathrm{H}, \mathrm{s}, \mathrm{H}_{8^{\prime \prime}}\right), 1.28\left(1 \mathrm{H}, \mathrm{m}, \mathrm{H}_{5^{\prime \prime}}\right), 1.03\left(3 \mathrm{H}, \mathrm{d}, J=6.6 \mathrm{~Hz}, \mathrm{H}_{9^{\prime \prime}}\right) .{ }^{13} \mathrm{C}$ NMR $\delta(p p m): 157.2\left(\mathrm{C}_{7}\right)$, $156.9\left(C_{5}\right), 156.0\left(C_{8 a}\right), 148.3\left(C_{2^{\prime \prime}}\right), 147.0\left(C_{7 a^{\prime \prime}}\right), 144.7\left(C_{3^{\prime}}\right), 144.6\left(C_{4^{\prime}}\right), 130.3\left(C_{1^{\prime}}\right), 118.0\left(C_{3 a^{\prime \prime}}\right)$, $117.7\left(C_{6^{\prime}}\right), 114.9\left(C_{2^{\prime}}\right), 114.8\left(C_{5^{\prime}}\right), 113.9\left(C_{3^{\prime \prime}}\right), 98.3\left(C_{4 a}\right), 95.2\left(C_{8}\right), 94.0\left(C_{6}\right), 75.1\left(C_{2}\right), 69.5$ $\left(C_{3}\right), 37.9\left(C_{4}\right), 31.9\left(C_{5^{\prime \prime}}\right), 30.8\left(C_{7^{\prime \prime}}\right), 29.2\left(C_{6^{\prime \prime}}\right), 21.5\left(C_{9^{\prime \prime}}\right), 19.6\left(C_{4^{\prime \prime}}\right), 7.8\left(C_{8^{\prime \prime}}\right)$. HRMS (ESI): $[\mathrm{M}+\mathrm{H}]^{+}$found with $\mathrm{m} / \mathrm{z} 439.1751$ (calculated for $\mathrm{C}_{25} \mathrm{H}_{27} \mathrm{O}_{7}$ : 439.1751).

\section{Analytical method (UHPLC-DAD-MS system)}

The liquid chromatography system was an Acquity ultra-high-pressure liquid chromatography (UHPLC) equipped with a photodiode array detector (DAD, Waters, Milford, MA). The column (HSS T3, $100 \times 2.1 \mathrm{~mm}, 1.8 \mathrm{~mm}$ ) contained a Nucleosil 120-3 C18 endcapped phase (MachereyNagel, Sweden). The flow rate was $0.55 \mathrm{~mL} \cdot \mathrm{min}^{-1}$ and the gradient conditions were as follows, 
except for experiments with menthofuran: solvent $A\left(\mathrm{H}_{2} \mathrm{O}-\mathrm{HCOOH}, 99: 1, v / v\right)$, solvent $B$

210

$\left(\mathrm{CH}_{3} \mathrm{CN}-\mathrm{H}_{2} \mathrm{O}-\mathrm{HCOOH}, 80: 19: 1, \mathrm{v} / \mathrm{v} / \mathrm{v}\right) ; 0-5 \mathrm{~min}, 0.1 \%$ to $40 \% \mathrm{~B}$ (linear gradient); 5-7 min, 40\% to $99 \%$ B (linear); 7-8 min, $99 \%$ B (isocratic); and $8-9 \mathrm{~min}, 99 \%$ to $0.1 \%$ B (linear). For the analyses involving menthofuran: $0-5 \mathrm{~min}, 0.1$ to $60 \%$ B (linear gradient); $5-7 \mathrm{~min}, 60 \%$ to $99 \%$ B (linear); 7-8 min, 99\% B (isocratic); and 8-9 min, 99\% to 0.1\% B (linear). The Acquity UHPLC system was coupled online with an amaZon X Ion-Trap mass spectrometer (Bruker Daltonics, Germany), with electrospray ionization operating in the positive ion mode. In the source, the nebulizer pressure was $44 \mathrm{psi}$, the temperature of dry gas was set at $200^{\circ} \mathrm{C}$ with a flow of $12 \mathrm{~L} \cdot \mathrm{min}^{-1}$ and the capillary voltage was set at $4 \mathrm{kV}$. The mass spectra were acquired over a $\mathrm{m} / \mathrm{z}$ range of $90-1500$. The speed of mass spectrum acquisition was set at $8100 \mathrm{~m} / \mathrm{z} \mathrm{s}^{-1}$.

\section{Peak identification and quantification}

The peaks from the UV chromatograms $(280 \mathrm{~nm})$ were attributed to the corresponding compounds by comparing the associated mass spectra and retention times to those obtained with authentic standards of (+)-C, (-)-EC, (-)-ECG, (-)-EGC and (-)-EGCG. The products resulting from the trapping of extension units by a nucleophile, i.e., (epi)catechin-( $4 \rightarrow \mathrm{X})$-nucleophile; or (E)C-NU, are not commercially available. Their mass spectra and retention times were determined by depolymerizing procyanidin B2 with the nucleophiles studied, as this reaction yields mainly epicatechin and the targeted EC-NU. The procyanidin depolymerization products obtained with 2-mercaptoethanol have also been characterized by NMR in a previous study. ${ }^{51}$ Figures 1 and S6 show examples of the UV chromatograms obtained along the kinetic experiments.

The molar responses at $280 \mathrm{~nm}$ of C, EC, ECG, EGC and EGCG were determined by calibration with the corresponding commercial standards. The molar responses at $280 \mathrm{~nm}$ of the (E)C-NU products were assessed by depolymerizing a procyanidin B2 sample with a large excess of 
nucleophile. As the amount of extension units trapped by the nucleophile (i.e., EC-NU) and EC produced from the terminal units were expected to be equal, the ratio of the corresponding peak area was attributed to the ratio of respective molar responses of the products. ${ }^{45,51}$ For ECG-PG, the molar response relative to EC of 3.7 given by Kennedy and Jones ${ }^{30}$ was applied. For ECG-MF and ECG-ME, a molar response relative to EC of 3.7 was used based on the coefficient experimentally determined for ECG, assuming that the nucleophile moiety did not alter the molar response of ECG. This assumption was consistent with the molar response of 1 relative to EC found for EC-MF and EC-ME. All values, expressed proportionally to EC molar response, are given in supporting information (Table S1).

\section{RESULTS AND DISCUSSION}

Experiments were first conducted on procyanidin B2 with 1 molar equivalent of nucleophile relatively to B2 (Scheme 2). Then, menthofuran, phloroglucinol and 2-mercaptoethanol were compared in the depolymerization of a grape seed commercial extract to characterize its tannin composition. Each nucleophile was used at the optimized concentration described earlier in standard literature procedures, while the other reaction conditions remained equal.

The analytical method using menthofuran was then compared to the Kennedy and Jones ${ }^{30}$ phloroglucinolysis method for the characterization of the tannin composition of another commercial tannin extract, pycnogenol ${ }^{9,10}$ and with mercaptolysis for the direct analysis of a grape pericarp powder and of a Douglas fir bark sample without prior extraction. ${ }^{51}$

\section{Depolymerization of procyanidin B2 with one molar equivalent of nucleophile}

The B2 dimer was chosen as a model of condensed tannins because its depolymerization conveniently yields only two products: $(2 \mathrm{R}, 3 \mathrm{R})$-epicatechin as the released terminal unit, and $(2 R, 3 R)$-epicatechin- $(4 \rightarrow X)$-nucleophile as the trapped extension unit, respectively referred 

quantified by the corresponding amounts of EC-NU produced, the reactions were carried out with a stoichiometric amount of each nucleophile with respect to procyanidin B2. Reactions were performed in methanol in the presence of $0.1 \mathrm{M} \mathrm{HCl}$, as in most of the standard methods.

The depolymerization tests were performed at $30^{\circ} \mathrm{C}$ to limit epimerization at $\mathrm{C} 2$ carbon atom of the flavanol unit that may occur following the ring opening in the acidic conditions. The percentages of EC-NU produced and of residual B2 with respect to initial B2 concentration were determined from the depolymerization experiments for the three nucleophiles tested (Table 1). The time required to reach the plateau of maximum EC-NU concentration is also indicated.

Menthofuran exhibited the highest efficiency to promote procyanidin B2 depolymerization under the reaction conditions applied. Indeed, an almost full consumption (>98.8\%) of the procyanidin B2 dimer was observed in $40 \mathrm{~min}$, with a recovery of $92 \%$ of the extension units in the form of EC-MF. Menthofuran purity $(\geq 95 \%)$ may have limited the calculated EC-MF yield as the nucleophile concentration was adjusted assuming $100 \%$ purity. The actual menthofuran to B2 dimer initial molar ratio was thus between $0.95: 1$ and $1: 1$. In contrast, the reactions performed with 2-mercaptoethanol (ME) and phloroglucinol (PG), prepared from $>99 \%$ pure products, reached an equilibrium with much lower proportions of EC-NU ( $41 \%$ of EC-ME and $23 \%$ of EC-PG, respectively), a lower proportion of terminal units, and a sizeable proportion of remaining B2 (5\% with ME and $14 \%$ with PG, see also Figure S7).

The differences between the initial B2 concentration and final of EC-NU, EC and residual B2 concentrations, likely correspond to oligomers that could not be accurately quantified in the UHPLC-DAD-MS analysis, even though dimers like EC- $(4 \rightarrow 8)-E C-(4 \rightarrow 2)-P G$ and trimers were observed in the chromatograms. Indeed, depolymerization products including EC-NU and EC, 
as well as procyanidin B2, are competitive nucleophiles that can add onto the cationic site of

282

283

284

285

286

287

288

extension units after cleavage, resulting in a large diversity of products and decreasing the yields in EC and EC-NU. The relative amounts of these oligomers could be assessed based on stoechiometry, from the difference between the amounts expressed in EC equivalents, of products formed $(\mathrm{EC}-\mathrm{NU}+\mathrm{EC})$ and $\mathrm{B} 2$ consumed at the considered reaction time. They were found to account for $39 \%$ and $53 \%$ of $B 2$ consumption in the reactions with 2mercaptoethanol and phloroglucinol, respectively, when the proportion of EC-NU reached its maximal value. In the case of menthofuran, they were estimated to account for $9 \%$ of B2 consumption.

The high initial reaction rate observed with phloroglucinol evidences its good reactivity as a trapping reagent, but the only partial depolymerization of the B2 dimer at reaction equilibrium shows that the EC-PG product is also cleaved at a high rate in a reverse reaction. Such an equilibrium between procyanidin B2 and EC-PG was predictable considering the structural similarity of these products. Indeed, they both consist in a phloroglucinol-like ring linked to the EC benzylic carbon at C2, and epicatechin-(4-2)-phloroglucinol also undergoes acidcatalyzed cleavage of the $(4 \rightarrow 2)$ bond in the reaction conditions applied. Other equilibria involving the new oligomers occurred at the same time, impacting the equilibrium between procyanidin B2 and EC-PG. The same phenomenon occurred with EC-ME, where the mercaptoethanol moiety can also be substituted in acidic conditions. ${ }^{32}$ Contrarily, the high yield of conversion of the B2 dimer into depolymerization products obtained with menthofuran in a 1:1 initial molar ratio indicate that EC-MF units were not significantly affected by this reversibility issue (Table 1). Menthofuran thus advantageously solves this concern by displacing strongly and rapidly the depolymerization equilibrium towards EC and EC-MF, even when this nucleophile is used in stoichiometric amount. 


\section{nucleophiles}

The promising results shown with menthofuran for the depolymerization of procyanidin B2 motivated the development of an analytical method for characterizing more complex proanthocyanidin extracts. Preliminary experiments carried out on a grape seed extract $\left(1 \mathrm{~g} \cdot \mathrm{L}^{-1}\right)$ showed that a 1:1 $(\mathrm{w} / \mathrm{w})$ menthofuran to extract weight ratio was sufficient to achieve maximal depolymerization yield of procyanidins. A comparison with phloroglucinol and 2-mercaptoethanol at the optimized ratios reported in literature was done by performing kinetic experiments at $30^{\circ} \mathrm{C}$ on $1 \mathrm{~g} \cdot \mathrm{L}^{-1}$ of the same grape seed extract in methanol containing $0.1 \mathrm{M} \mathrm{HCl}$. In these experiments, 10:1 and 55:1 (w/w) nucleophile to extract ratios were used for phloroglucinol and 2-mercaptoethanol, respectively, corresponding to the $10: 1(\mathrm{w} / \mathrm{w})$ weight ratio defined by Kennedy and Jones ${ }^{30}$ for phloroglucinol and to the $5 \%(\mathrm{v} / \mathrm{v})$ volume ratio proposed by Tanaka and coworkers ${ }^{31,35}$ for 2-mercaptoethanol. In the extreme case where the tannin extract would consist only of EC extension monomers (molecular weight $\left.290 \mathrm{~g} \cdot \mathrm{mol}^{-1}\right)$, these weight ratios corresponded to a molar excess of nucleophile of 2, 23 and 200 for menthofuran, phloroglucinol and 2-mercaptoethanol, respectively.

The depolymerization products were categorized in four types of units, considering on one hand, extension units versus terminal units and on the other hand, galloylated units versus non-galloylated units (Figure 2). For instance, the C-NU and EC-NU concentrations measured were summed to evaluate the amount of non-galloylated extension units. This enabled to infer the average composition in constitutive units of the polymers.

The release of non-galloylated units and of galloylated units followed different kinetics. The maximum concentration of non-galloylated units was reached faster (after 120-150 min) than that of galloylated units (after 200-300 min). It can also be noted that the amount of non- 
galloylated units decreased over time, contrary to galloylated units, indicating higher stability of the latter. These results point to the importance of performing complete kinetic experiments when characterizing tannin composition instead of selecting an arbitrary time, because this optimal time may vary depending on the tannin extract. This is especially important when reactions are slow, which can lead to numerous side-reactions.

The concentrations reached at the plateau in the kinetic experiments were used to calculate the weight percentages of the four types of constitutive units obtained with each nucleophile for the grape seed extract (Table 2). In each case, depolymerizable units represented around $46 \%(w / w)$ of the grape seed extract and consisted of around $25 \%$ of extension units, $13 \%$ of terminal units, $5 \%$ of galloylated extension units and $2 \%$ of galloylated terminal units. The results were thus comparable despite the different amounts of nucleophile applied.

The analytical depolymerization involving menthofuran as the nucleophilic reagent thus demonstrated the same performance as with 10- and 100-times higher amounts of

342 phloroglucinol and 2-mercaptoethanol, respectively. To our knowledge, this makes menthofuran the only nucleophilic trapping reagent described so far that enables the

344 depolymerization of condensed tannins with maximal yield using a near to quantitative 345 nucleophile to procyanidins molar ratio.

\section{Comparison of furanolysis with standard methods}

347 The high efficiency of menthofuran to trap the extension units released from tannin depolymerization led to evaluate its use in comparison with the phloroglucinolysis developed 349 by Kennedy and Jones ${ }^{30}$ and with mercaptolysis based on the work of Tanaka et al. ${ }^{31}$ Figure $3 \mathrm{~A}$ compares the results of the analysis of a maritime pine bark extract, commercially

351 available under the name pycnogenol, using a 1:1 (w/w) weight ratio of menthofuran to 352 procyanidin extract and a 10:1 (w/w) weight ratio of phloroglucinol to procyanidin extract as 
optimized in the standard method. Both reactions were performed in methanol containing $0.1 \mathrm{M} \mathrm{HCl}$. Reaction with menthofuran, performed at $30^{\circ} \mathrm{C}$ for $90 \mathrm{~min}$, resulted in a very similar procyanidin composition profile as phloroglucinolysis $\left(50^{\circ} \mathrm{C}, 20 \mathrm{~min}\right)$, with a good reproducibility and equivalent depolymerization yields, although a 10-fold lower nucleophile to extract weight ratio was used. This represented a non-negligible saving of reactants.

The menthofuran method was also compared to mercaptolysis for the characterization of the proanthocyanidin fractions of a grape pericarp powder. These methods were applied directly on the biomass sample (i.e., without prior extraction of tannins), in methanol containing $0.1 \mathrm{M}$ $\mathrm{HCl}$. Furanolysis was performed with a 1:1 weight ratio of menthofuran to grape pericarp powder at $30^{\circ} \mathrm{C}$ for $2 \mathrm{~h}$, while mercaptolysis was performed with a 5.5:1 weight ratio of 2mercaptoethanol to grape pericarp powder at $40^{\circ} \mathrm{C}$ for $2 \mathrm{~h}$. Chromatograms are given as supporting information (Figures S8 and S9). Both methods showed similar results and good reproducibility (Figure 3B), despite using a 10-fold lower molar amount of nucleophile for furanolysis.

The menthofuran method was also applied to the direct analysis of Douglas fir bark powder, without a preliminary extraction step. The depolymerization products reached their maximal concentration after $20 \mathrm{~h}$, yielding a procyanidin content of $3.9 \%(\mathrm{w} / \mathrm{w})$ of biomass dry weight, including $3.2 \pm 0.2 \%$ of extension units and $0.7 \pm 0.0 \%$ of terminal units. On the same sample, direct mercaptolysis (selected for reference since the standard phloroglucinolysis protocol first proceeds with tannin extraction) gave a similar procyanidin content ( $3.7 \% \mathrm{w} / \mathrm{w})$, including $3.0 \pm 0.1 \%$ extension units and $0.7 \pm 0.0 \%$ terminal units. It should be noted that mercaptolysis was faster (the maximal concentration was reached in $4 \mathrm{~h}$ ) due to the higher temperature $\left(40^{\circ} \mathrm{C}\right.$ vs. $\left.30^{\circ} \mathrm{C}\right)$ and the high nucleophile excess (60-times higher than menthofuran) used in this method. The differences in polarity and solvation of the 
nucleophiles may also affect the depolymerization kinetics through mass transfer limitations within the solid bark sample.

Menthofuran thus displays interesting properties as a trapping reagent for the analytical depolymerization of procyanidins. Its high efficiency allows its use at low concentration, contrary to the large molar excesses required with the classical nucleophiles, and low temperature for a fast conversion of condensed tannins into monomeric units without significant reversal of the reaction. It is a readily available commercial chemical, and its use in near to stoichiometric amounts contributes to save cost and to lower the exposure to reactants. In the same way to the other nucleophiles, adjustments may be required in the protocol according to the sample to be analyzed. Since the amount of procyanidin in the sample is unknown, the quantity of menthofuran needs to be estimated to ensure it is higher than the quantity of extension units. Also, like with the other nucleophiles and methods, the minimum reaction time required to reach the maximum depolymerization yield may vary according to the sample (plant species, organ and physiological status affect tannin concentration and constitutive unit composition) and especially according to its type of preparation (ground raw biomass or more or less purified extracts). The good stability of the depolymerization products in the presence of menthofuran at $30^{\circ} \mathrm{C}$ enables to use a single, longer than required reaction time for samples of a same type when (recommended) systematic kinetics experiments cannot be performed. As a general guideline, the following conditions may be applied for unknown samples.

For the characterization of tannins in soluble extracts, the following reaction conditions are proposed as a standard setup: the depolymerization of a $1 \mathrm{~g} \cdot \mathrm{L}^{-1}$ tannin extract in methanol in the presence of $0.1 \mathrm{M} \mathrm{HCl}$ is carried out with $1 \mathrm{~g} \cdot \mathrm{L}^{-1}$ menthofuran at $30^{\circ} \mathrm{C}$ over $2 \mathrm{~h}$, either with end-point analysis or, preferably when possible, following the complete kinetics. 
401

402

403

404

405

406

407

408

409

410

411

412

413

414

415

416

417

418

For the direct analysis of raw biomass, a concentration of $10 \mathrm{~g} \cdot \mathrm{L}^{-1}$ of dry biomass sample may allow a good response in LC-DAD(-MS), using $2 \mathrm{~g} \cdot \mathrm{L}^{-1}$ menthofuran. Compared to soluble extracts, mass transfer limitations may require a longer reaction time, as shown with the analysis of the bark sample, for which the reaction was complete in 20h. Alternatively, menthofuran concentration can also be increased to speed up the reaction. As the water content of raw biomass samples may affect the efficiency and rate of the depolymerization process, it is advisable to dry such samples to less than $15 \%$ water $(w / w)$.

At appropriate times, the reaction medium can be directly analyzed by a LC-DAD(-MS) system according to a protocol similar as the one given in Material \& Methods. When significant delays are expected between the reaction and the analysis of the reaction products, for example when large series of samples are scheduled in parallel, it is preferred to raise the $\mathrm{pH}$ of the reaction medium to $\mathrm{pH} \mathrm{4-5} \mathrm{after} \mathrm{the} \mathrm{reaction} \mathrm{is} \mathrm{over,} \mathrm{in} \mathrm{order} \mathrm{to} \mathrm{avoid} \mathrm{side-reactions.}$

On a more general note, the menthofuran method, referred to as furanolysis, demonstrates the potential of furans as nucleophilic trapping reagents in the depolymerization of condensed tannins. In a former work, furan and sylvan, two compounds that can be obtained by conversion of $\mathrm{C} 5$ sugars from wood biomass, were indeed proven to be efficient nucleophiles for quantitatively supplying fully biobased building blocks from condensed tannins. ${ }^{44,45}$ The superior efficiency of the menthofuran method needs to be tested against tannin structures known to be more recalcitrant to the usual depolymerization conditions, such as 5-deoxy tannins or A-type proanthocyanidins, using harsher conditions (e.g., higher temperature and/or acid concentration).

\section{ABBREVIATIONS USED}


424 Flavanols: B2, procyanidin B2 or B2 dimer; C, catechin; CG, catechin-3-O-gallate; EC, 425 epicatechin; ECG, epicatechin-3-O-gallate; EGC, epigallocatechin; EGCG, epigallocatechin-3-O426 gallate. Nucleophiles: ME, mercaptoethanol; MF, menthofuran; PG, phloroglucinol; NU, 427 nucleophile. Flavanol derivatives (representative examples of the numerous combinations, 428 see also Schemes 1 \& 2): C-ME, catechin-(4 $\rightarrow 2 S)$-mercaptoethanol; EC-MF,

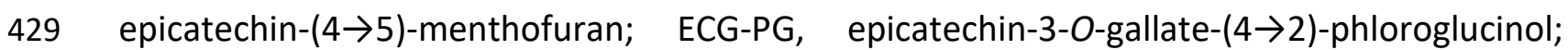
430 EGCG-NU, epigallocatechin-3-O-gallate-(4 $\rightarrow$ X)-nucleophile; (E)CG-NU, (epi)catechin-3-O431 gallate- $(4 \rightarrow \mathrm{X})$-nucleophile.

\section{FUNDING SOURCES}

433 The study was performed with financial support from European Union's Horizon 2020 434 research and innovation program (grant agreement No 688338), INRA and Montpellier 435 Supagro.

\section{SUPPORTING INFORMATION}

437 UV chromatograms $(280 \mathrm{~nm})$ of the grape seed extract depolymerized with menthofuran 438 throughout the kinetic experiment. Detailed kinetics of the depolymerization tests performed 439 on procyanidin B2 with 1 molar equivalent. UV chromatograms ( $280 \mathrm{~nm}$ ) of the products of 440 depolymerization of the grape pericarp powder containing procyanidins and prodelphinidins 441 with menthofuran and 2-mercaptoethanol. 


\section{REFERENCES}

443 (1) Geissman, T. A.; Dittmar, H. F. K. A proanthocyanidin from avocado seed. Phytochemistry 1965, 4, 359-368.

(2) Hemingway, R. W. Structural variations in proanthocyanidins and their derivatives. In Chemistry and Significance of Condensed Tannins; Hemingway, R. W., Karchesy, J. J., Branham, S. J., Eds.; Plenum Press: New York and London, 1989; pp 83-107.

(3) Quideau, S.; Deffieux, D.; Douat-Casassus, C.; Pouységu, L. Plant polyphenols: Chemical properties, biological activities, and synthesis. Angew. Chem. Int. Ed. 2011, 50, 586-621.

(4) Matthews, S.; Mila, I.; Scalbert, A.; Pollet, B.; Lapierre, C.; Hervé du Penhoat, C. L. M.; their acid depolymerization in the presence of nucleophiles. J. Agric. Food Chem. 1997, $45,1195-1201$.

(5) Hernes, P. J.; Hedges, J. I. Determination of condensed tannin monomers in environmental samples by capillary gas chromatography of acid depolymerization extracts. Anal. Chem. 2000, 72, 5115-5124.

(6) Bate-Smith, E. C. The phenolic constituents of plants and their taxonomic significance. I. Dicotyledons. J. Linn. Soc. Lond. Bot. 1962, 58, 95-173.

(7) Pizzi, A.; Cameron, F. A. Flavonoid tannins - Structural wood components for drought-

(8) Mellway, R. D.; Tran, L. T.; Prouse, M. B.; Campbell, M. M.; Constabel, C. P. The wound, pathogen-, and ultraviolet B-responsive MYB134 gene encodes an R2R3 MYB transcription factor that regulates proanthocyanidin synthesis in poplar. Plant Physiol. 2009, 150, 924-941. 
465

466

467

468

469

470

471

472

473

474

475

476

477

478

479

480

481

482

483

484

485

486

487

488

(9) Schoonees, A.; Visser, J.; Musekiwa, A.; Volmink, J. Pycnogenol ${ }^{\circledR}$ (extract of French maritime pine bark) for the treatment of chronic disorders. Cochrane Database Syst. Rev. 2012, 4, CD008294.

(10) Cretu, E.; Karonen, M.; Salminen, J. P.; Mircea, C.; Trifan, A.; Charalambous, C.; Constantinou, A. I.; Miron, A. In vitro study on the antioxidant activity of a polyphenolrich extract from Pinus brutia bark and its fractions. J. Med. Food 2013, 16, 984-991.

(11) Espley, R. V.; Butts, C. A.; Laing, W. A.; Martell, S.; Smith, H.; McGhie, T. K.; Zhang, J.; Paturi, G.; Hedderley, D.; Bovy, A.; Schouten H. J.; Putterill, J.; Allan, A. C.; Hellens, R. P. Dietary flavonoids from modified apple reduce inflammation markers and modulate gut microbiota in mice. J. Nutr. 2014, 144, 146-154.

(12) Brosse, N.; Pizzi, A. Tannins for wood adhesives, foams and composites. In Bio-based Wood Adhesives: Preparation, Characterization, and Testing; Zhonqi, H., Ed.; CRC Press, 2017; pp 197-220.

(13) Rouméas, L.; Fulcrand, H.; Aouf, C.; Dubreucq, E. Biosourced compound having epoxide functions, method for the synthesis of such a compound, and use thereof for producing epoxy resin. WO Patent 2016 / 174334 A1, Nov 3, 2016.

(14) Fulcrand, H.; Rouméas, L.; Billerach, G.; Aouf, C.; Dubreucq, E. Advances in bio-based thermosetting polymers. In Recent Advances in Polyphenol Research 6; Halbirth, H., Stich, K., Cheynier, V., Quideau, S., Eds.; John Wiley \& Sons, Ltd, 2019; pp 285-334.

(15) Everette, J. D.; Bryant, Q. M.; Green, A. M.; Abbey, Y. A.; Wangila, G. W.; Walker, R. B. Thorough study of reactivity of various compound classes toward the Folin-Ciocalteu reagent. J. Agric. Food Chem. 2010, 58, 8139-8144.

(16) Guyot, S.; Le Guernevé, C.; Marnet, N.; Drilleau, J. F. Methods for determining the degree of polymerization of condensed tannins: A new ${ }^{1} \mathrm{H}$ NMR procedure applied to 
cider apple procyanidins. In Plant Polyphenols 2: Chemistry, Biology, Pharmacology,

490

491

492

493

494

495

496

497

498

499

500

501

502

503

504

505

506

507

508

509

510

511

Ecology; Gross, G. G., Hemingway, R. W., Yoshida, T., Branham, S. J., Eds.; Kluwer Academic/Plenum Publishers: New York, 1999; pp 211-222.

(17) Newman, R. H.; Porter, L. J.; Foo, L. Y.; Johns, S. R.; Willing, R. I. High-resolution ${ }^{13}$ C NMR studies of proanthocyanidin polymers (condensed tannins). Magn. Reson. Chem. 1987, $25,118-124$.

(18) Brown, R. H.; Mueller-Harvey, I.; Zeller, W. E.; Reinhardt, L.; Stringano, E.; Gea, A.; Drake, C.; Ropiak, H. M.; Fryganas, C.; Ramsay, A.; Hardcastle, E. E. Facile purification of milligram to gram quantities of condensed tannins according to mean degree of polymerization and flavan-3-ol subunit composition. J. Agric. Food Chem. 2017, 65, 8072-8082.

(19) Mouls, L.; Hugouvieux, V.; Mazauric, J.-P.; Sommerer, N.; Mazerolles, G.; Fulcrand, H. How to gain insight into the polydispersity of tannins: A combined MS and LC study. Food Chem. 2014, 165, 348-353.

(20) Pasch, H.; Pizzi, A.; Rode, K. MALDI-TOF mass spectrometry of polyflavonoid tannins. Polymer 2001, 42, 7531-7539.

(21) Taylor, A. W.; Barofsky, E.; Kennedy, J. A.; Deinzer, M. L. Hop (Humulus lupulus L.) proanthocyanidins characterized by mass spectrometry, acid catalysis, and gel permeation chromatography. J. Agric. Food Chem. 2003, 51, 4101-4110.

(22) Naumann, H.; Sepela, R.; Rezaire, A.; Masih, S.E.; Zeller, W.E.; Reinhardt, L.A.; Robe, J.T.; Sullivan, M.L.; Hagerman, A.E. Relationships between structures of condensed tannins from texas legumes and methane production during in vitro rumen digestion. Molecules 2018, 23, 2123-2139. 
(23) Engström M.T.; Maija Pälijärvi M.; Fryganas C.; Grabber J.H.; Mueller-Harvey I.; Salminen J.P. Rapid qualitative and quantitative analyses of proanthocyanidin oligomers and polymers by UPLC-MS/MS. J. Agric. Food Chem. 2014, 62, 3390-3399.

(24) Li, H.J.; Deinzer, M.L. Tandem mass spectrometry for sequencing proanthocyanidins. Anal. Chem. 2007, 79, 1739-1748.

(25) Hemingway, R. W. Reactions at the interflavanoid bond of proanthocyanidins. In Chemistry and significance of condensed tannins; Hemingway, R. W., Karchesy, J. J., Branham S. J., Eds.; Plenum Press: New York and London, 1989; pp 265-283.

(26) Karchesy, J. J.; Hemingway, R. W. Condensed tannins: $(4 \beta \rightarrow 8 ; 2 \beta \rightarrow O \rightarrow 7)$-Linked procyanidins in Arachis hypogea L. J. Agric. Food Chem. 1986, 34, 966-970.

(27) Mouls, L.; Fulcrand, H. UPLC-ESI-MS study of the oxidation markers released from tannin depolymerization: Toward a better characterization of the tannin evolution over food and beverage processing. J. Mass Spectrom. 2012, 47, 1450-1457.

(28) Betts, M. J.; Brown, B. R.; Brown, P. E.; Pike, W. T. Degradation of condensed tannins: Structure of the tannin from common heather. Chem. Commun. Lond. 1967, 11101112.

(29) Foo, L. Y.; McGraw, G. W.; Hemingway, R. W. Condensed tannins: preferential substitution at the interflavanoid bond by sulphite ion. J. Chem. Soc. Chem. Commun. 1983, 672-673.

(30) Kennedy, J. A.; Jones, G. P. Analysis of proanthocyanidin cleavage products following acid-catalysis in the presence of excess phloroglucinol. J. Agric. Food Chem. 2001, 49, 1740-1746. 
(31) Tanaka, T.; Takahashi, R.; Kouno, I.; Nonaka, G. Chemical evidence for the deastringency (insolubilization of tannins) of persimmon fruit. J. Chem. Soc., Perkin Trans. 1 1994, 3013-3022.

(32) Brown, B. R.; Shaw, M. R. Reactions of flavanoids and condensed tannins with sulphur nucleophiles. J. Chem. Soc., Perkin Trans. 1 1974, 2036-2049.

(33) Ramirez-Coronel, M. A.; Marnet, N.; Kolli, V. S. K.; Roussos, S.; Guyot, S.; Augur, C. Characterization and estimation of proanthocyanidins and other phenolics in coffee pulp (Coffea arabica) by thiolysis-high-performance liquid chromatography. J. Agric. Food Chem. 2004, 52, 1344-1349.

(34) Gea, A.; Stringano, E.; Brown, R. H.; Mueller-Harvey, I. In situ analysis and structural elucidation of sainfoin (Onobrychis viciifolia) tannins for high-throughput germplasm screening. J. Agric. Food Chem. 2011, 59, 495-503.

(35) Orejola, J.; Matsuo, Y.; Saito, Y.; Tanaka, T. Characterization of proanthocyanidin oligomers of Ephedra sinica. Molecules 2017, 22, 1308.

(36) Gao, C.; Cunningham, D. G.; Liu, H.; Khoo, C.; Gu, L. Development of a thiolysis HPLC method for the analysis of procyanidins in cranberry products. J. Agric. Food Chem. 2018, 66, 2159-2167.

(37) Pinasseau, L.; Verbaere, A.; Roques, M.; Meudec, E.; Vallverdú-Queralt, A.; Terrier, N.; Boulet, J.-C.; Cheynier, V.; Sommerer, N. A fast and robust UHPLC-MRM-MS method to characterize and quantify grape skin tannins after chemical depolymerization. Molecules 2016, 21, 1409.

(38) Thompson, R. S.; Jacques, D.; Haslam, E.; Tanner, R. J. N. Plant proanthocyanidins. Part I. Introduction; The isolation, structure, and distribution in nature of plant procyanidins. J. Chem. Soc., Perkin Trans. 1 1972, 1387-1399. 
558

559

560

561

562

563

564

565

566

567

568

569

570

571

572

573

574

575

576

577

578

579

580

581

(39) Fletcher, A. C.; Porter, L. J.; Haslam, E. Hindered rotation and helical structures in natural procyanidins. J. Chem. Soc. Chem. Commun. 1976, 627-629.

(40) European Chemicals Agency. 2-Mercaptoethanol - Registration dossier https://echa.europa.eu/fr/registration-dossier/-/registered-dossier/2206/7/3/2 (last accessed Jan 21, 2019).

(41) Fairchild, E. J.; Stokinger, H. E. 1. Acute toxicity of some aliphatic and aromatic thiols (mercaptans). Am. Ind. Hyg. Assoc. J. 1958, 19, 171-189.

(42) Andersen F. A. Final report on the safety assessment of phloroglucinol. J. Am. Coll. Toxicol. 1995, 14, 468-475.

(43) Fu, C.; Chen, W.; Quek, Y. L.; Ni, R.; Ghani, A. B. A.; Leong, W. W. Y.; Zeng, H.; Huang, D. Sustainability from agricultural waste: Chiral ligands from oligomeric proanthocyanidins via acid-mediated depolymerization. Tetrahedron Lett. 2010, 51, 6322-6324.

(44) Rouméas, L.; Fulcrand, H.; Aouf, C.; Dubreucq, E. Flavonoid derivative compounds and method for preparing same by depolymerisation of condensed tannins. WO Patent 2016 / 020615 A1, Feb 11, 2016.

(45) Rouméas, L.; Billerach, G.; Aouf, C.; Dubreucq, É.; Fulcrand, H. Furylated flavonoids: Fully biobased building blocks produced by condensed tannins depolymerization. ACS Sustain. Chem. Eng. 2018, 6, 1112-1120.

(46) Gordon, W. P.; Forte, A. J.; McMurtry, R. J.; Gal, J.; Nelson, S. D. Hepatotoxicity and pulmonary toxicity of pennyroyal oil and its constituent terpenes in the mouse. Toxicol. Appl. Pharmacol. 1982, 65, 413-424.

(47) Gordon, W. P.; Huitric, A. C.; Seth, C. L.; McClanahan, R. H.; Nelson, S. D. The metabolism of the abortifacient terpene, $(\mathrm{R})-(+)$-pulegone, to a proximate toxin, menthofuran. Drug Metab. Dispos. 1987, 15, 589-594. 
(48) Adams, T. B.; Hallagan, J. B.; Putnam, J. M.; Gierke, T. L.; Doull, J.; Munro, I. C.; Newberne, P.; Portoghese, P. S.; Smith, R. L.; Wagner, B. M.; Weil, C. S.; Woods, L. A.; Ford, R. A. The FEMA GRAS assessment of alicyclic substances used as flavour ingredients. Food Chem. Toxicol. 1996, 34, 763-828.

(49) Pulegone and menthofuran in flavourings - Opinion of the scientific panel on food additives, flavourings, processing aids and materials in contact with food (AFC). EFSA J. 2008, 6, 298.

(50) Brillouet J.M.; Fulcrand H.; Carrillo S.; Rouméas L.; Romieu C. Isolation of native proanthocyanidins from grapevine (Vitis vinifera) and other fruits in aqueous buffer. J. Agric. Food Chem. 2017, 65, 2895-2901.

(51) Rouméas, L.; Aouf, C.; Dubreucq, E.; Fulcrand, H. Depolymerisation of condensed tannins in ethanol as a gateway to biosourced phenolic synthons. Green Chem. 2013, $15,3268-3275$. 
597

598

599

600

601

602

603

604

605

606

607

608

609

610

611

612

613

614

615

616

617

Scheme 1: Depolymerization of procyanidins leading to the release of terminal units and the trapping of extension units by a nucleophile (example of the products obtained with menthofuran).

Scheme 2: Other procyanidin derivatives encountered in this study. Abbreviations: C, catechin; EC, epicatechin; CG, catechin-3-O-gallate; ECG, epicatechin-3-O-gallate; PG, phloroglucinol; ME, mercaptoethanol.

Figure 1: UV chromatograms $(280 \mathrm{~nm})$ of $(A)$ the grape seed extract dissolved in methanol $\left(1 \mathrm{~g} \cdot \mathrm{L}^{-1}\right)$ and $(\mathrm{B})$ the same extract after acid-catalyzed depolymerization with menthofuran (1 g.L-1 ; 65 min reaction). 1: C (291 m/z), 2: EC (291 m/z), 3: ECG (443 m/z), 4: C-MF (439 m/z), 5: EC-MF (439 m/z), 6: ECG-MF (591 m/z).

Figure 2: Depolymerization kinetics of the procyanidins contained in the grape seed extract according to the nucleophile used: menthofuran, phloroglucinol or 2-mercaptoethanol. Extension units ( $\mathrm{C}-\mathrm{NU}+\mathrm{EC}-\mathrm{NU})$ are represented by red circles, terminal units $(\mathrm{C}+\mathrm{EC})$ by blue squares, galloylated extension units (ECG-NU) by purple triangles and galloylated terminal units (ECG) by green diamonds. Experimental points are means and error bars are standard deviations, calculated from three independent kinetic experiments.

Figure 3: Comparison of the menthofuran method (A) with a standard phloroglucinol method through the characterization of a pine bark extract (pycnogenol), (B) with mercaptolysis through the characterization of a grape pericarp powder containing procyanidins and 
621 from three independent experiments. 


\section{TABLES}

Table 1: Procyanidin B2 conversion yields in the presence of 1 molar equivalent of nucleophiles

$\begin{array}{lcccc}\text { Nucleophile } & \begin{array}{c}\text { Time to reach } \\ \text { the plateau }\end{array} & \begin{array}{c}\text { EC-NU production yield } \\ \text { at } t_{\max }\end{array} & \begin{array}{c}\text { EC production yield } \\ \text { at } t_{\max }\end{array} & \begin{array}{c}\text { Remaining B2 dimer } \\ \text { at } t_{\max }\end{array} \\ & (\mathrm{h}) & \begin{array}{c}\text { mol\% of theoretical } \\ \text { maximum }\end{array} & \begin{array}{c}\text { mol\% of theoretical } \\ \text { maximum }\end{array} & \begin{array}{c}\text { mol\% of initial B2 } \\ \text { concentration }\end{array} \\ \text { Menthofuran } & 0.7 & 91.6 \pm 1.1 & 88.1 \pm 1.9 & 1.2 \pm 0.0 \\ \text { 2-Mercaptoethanol } & 2.0 & 40.5 \pm 0.4 & 74.9 \pm 2.1 & 5.4 \pm 0.7 \\ \text { Phloroglucinol } & 0.2 & 22.5 \pm 0.4 & 65.8 \pm 0.7 & 14.1 \pm 0.1 \\ t_{\text {max: }} \text { time at which the plateau of maximum EC-NU concentration is reached } & & \\ \text { ithe theoretical maximum corresponds to the conversion of } 1 \text { mol B2 dimer into } 1 \text { mol EC plus } 1 \text { mol EC-NU. } \\ \text { Values of mean and standard deviation were determined by performing three independent experiments. }\end{array}$

Table 2: Composition in procyanidin constitutive units of a grape seed extract according to the nucleophile used for its characterization.

$\begin{array}{lcccc}\text { Nucleophile } & \begin{array}{c}\text { Extension } \\ \text { Units } \\ \%(\mathrm{w} / \mathrm{w})^{\mathrm{i}}\end{array} & \begin{array}{c}\text { Terminal Units }^{\mathrm{b}} \\ \%(\mathrm{w} / \mathrm{w})^{\mathrm{i}}\end{array} & \begin{array}{c}\text { Galloylated } \\ \text { Extension Units }^{\mathrm{c}} \\ \%(\mathrm{w} / \mathrm{w})^{\mathrm{ii}}\end{array} & \begin{array}{c}\text { Galloylated } \\ \text { Terminal Units } \\ \%(\mathrm{w} / \mathrm{w})^{\mathrm{i}}\end{array} \\ \text { Menthofuran } & 25.9 \pm 0.4 & 13.1 \pm 0.3 & 5.2 \pm 0.1 & 1.6 \pm 0.0 \\ \text { 2-Mercaptoethanol } & 25.0 \pm 0.3 & 12.9 \pm 0.2 & 5.1 \pm 0.1 & 1.6 \pm 0.0 \\ \text { Phloroglucinol } & 25.6 \pm 0.3 & 12.5 \pm 0.2 & 5.2 \pm 0.2 & 1.6 \pm 0.0\end{array}$

Compositions calculated from the plateau of maximum concentration of ${ }^{a}: C-N U+E C-N U,{ }^{b}: C+E C,{ }^{c}: E C G-N U,{ }^{d}: E C G$

\footnotetext{
i,ii Mean values and standard deviations were calculated for each nucleophile from three independent kinetic experiments using concentrations at (i) three reaction times (9 experimental points) and (ii) two reaction times (6 experimental points).
} 


\section{FIGURE GRAPHICS}

\section{Scheme 1}

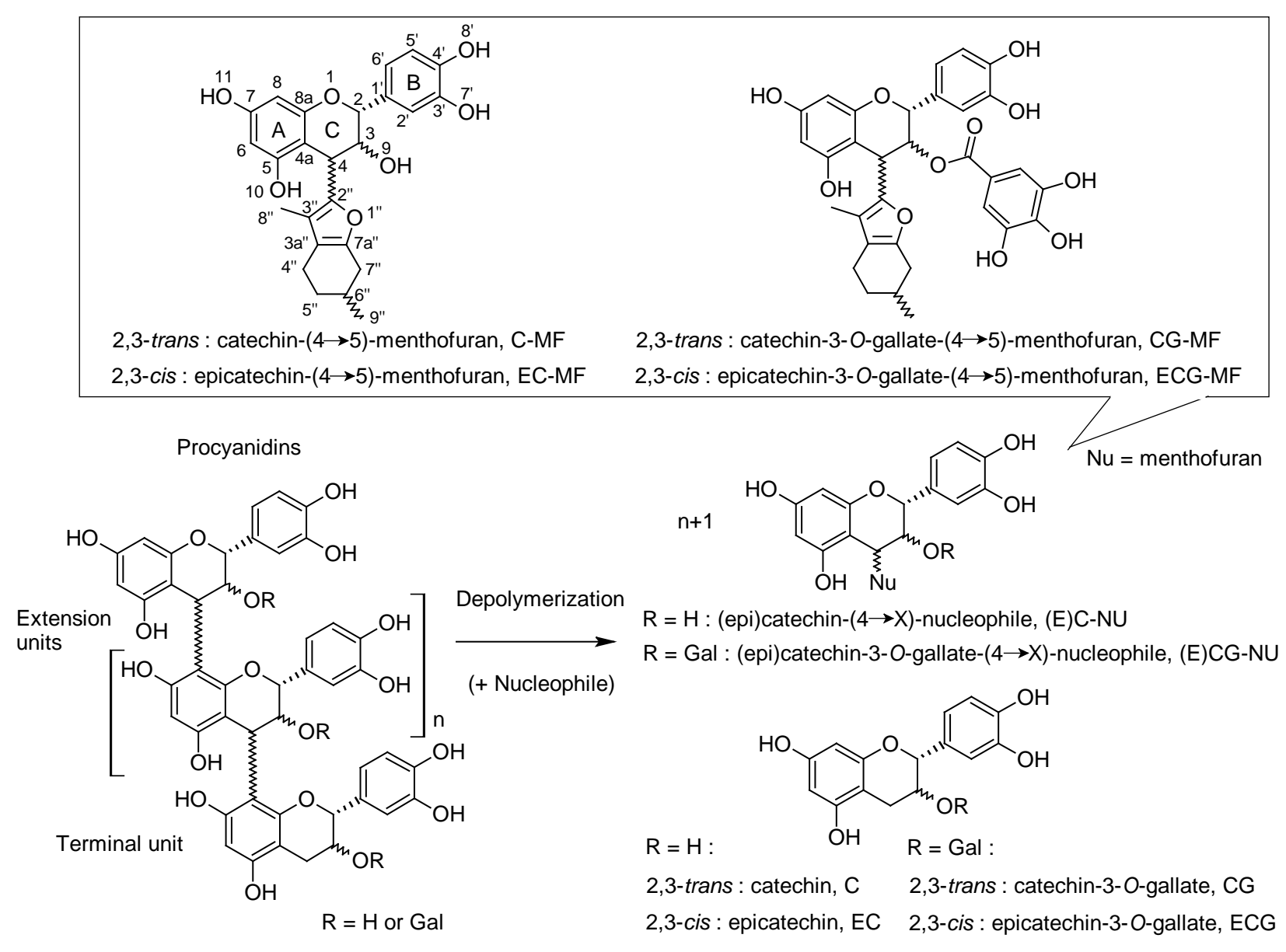


<smiles>[R6]c1cc([C@@H]2Oc3cc(O)cc(O)c3[C@@H](c3c(O)cc(O)cc3O)[C@H]2[R6])cc(O)c1O</smiles><smiles>[R2]c1cc([C@H]2Oc3cc(O)cc(O)c3[C@@H](SCCO)[C@H]2[R20])cc(O)c1O</smiles>
$\mathrm{R}_{1}=\mathrm{H} \quad \mathrm{R}_{1}=\mathrm{Gal}$

$\mathrm{R}_{1}=\mathrm{H} \quad \mathrm{R}_{1}=\mathrm{Gal}$

$\mathbf{R}_{\mathbf{2}}=\mathbf{H} \quad$ (E)C-PG (E)CG-PG

$\mathbf{R}_{\mathbf{2}}=\mathbf{O H}(\mathrm{E}) \mathrm{GC}-\mathrm{PG}$ (E)GCG-PG

$$
\begin{array}{lll}
\mathbf{R}_{\mathbf{2}}=\mathbf{H} & \text { (E)C-ME } & \text { (E)CG-ME } \\
\mathbf{R}_{\mathbf{2}}=\mathbf{O H} & (\mathrm{E}) \mathrm{GC}-\mathrm{ME} & \text { (E)GCG-ME }
\end{array}
$$<smiles>Oc1cc(O)c2c(c1)O[C@H](c1ccc(O)c(O)c1)[C@H](O)C2c1c(O)cc(O)c2c1O[C@H](c1ccc(O)c(O)c1)[C@H](O)C2</smiles>

Procyanidin B2

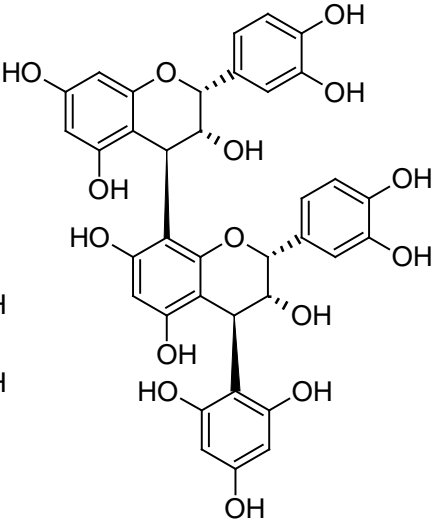

Epicatechin- $(4 \beta \rightarrow 8)$-epicatechin-

$(4 \beta \rightarrow 8)$-phloroglucinol, EC-EC-PG 
Figure 1
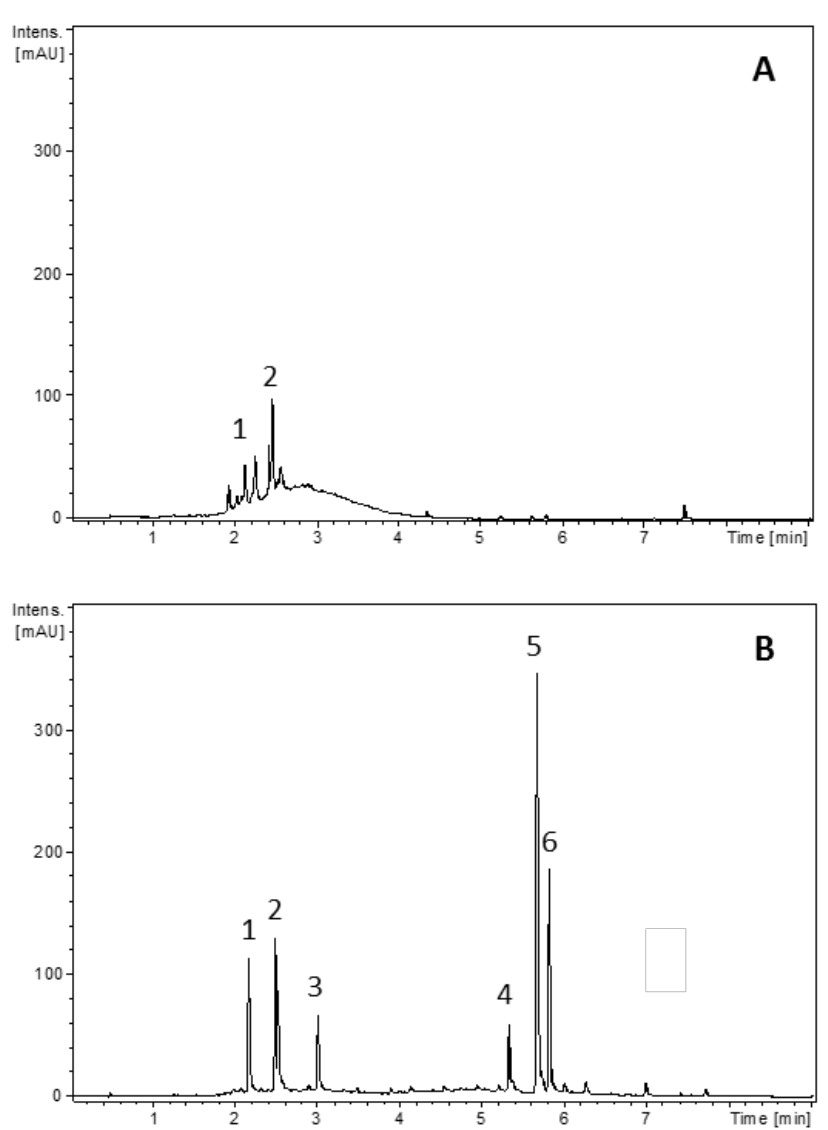
Figure 2

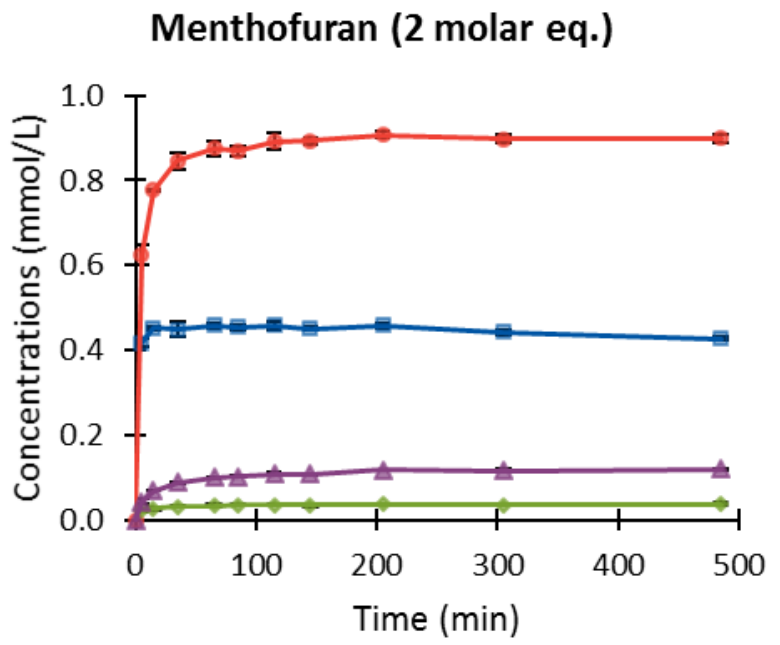

Phloroglucinol (23 molar eq.)

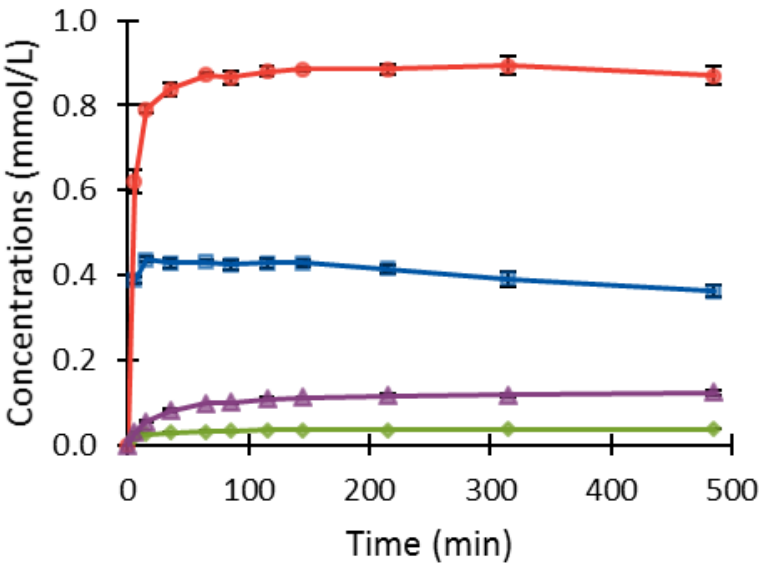

2-Mercaptoethanol (200 molar eq.)

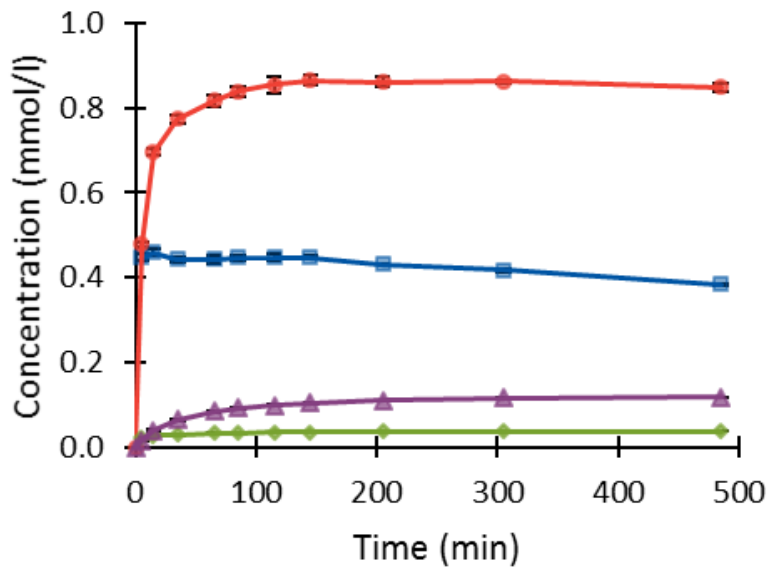

$\longrightarrow$ Extension units

$\because$-Terminal units

- Galloylated extension units

$\rightarrow$ Galloylated terminal units 
Figure 3

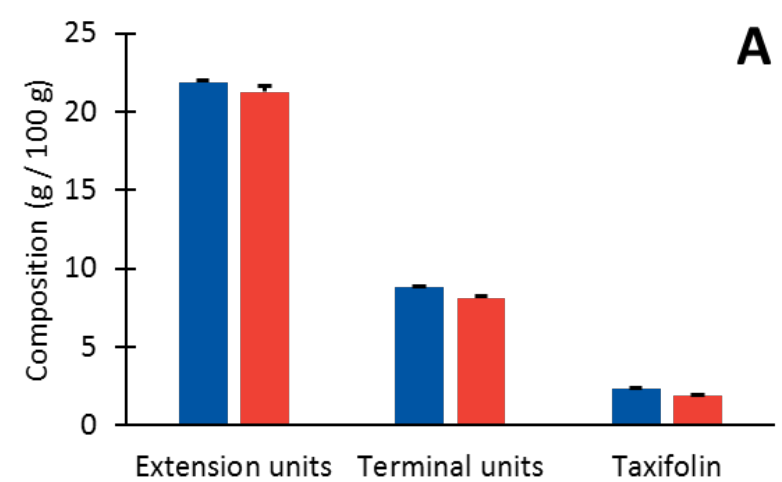

- Menthofuran method a Phloroglucinol method

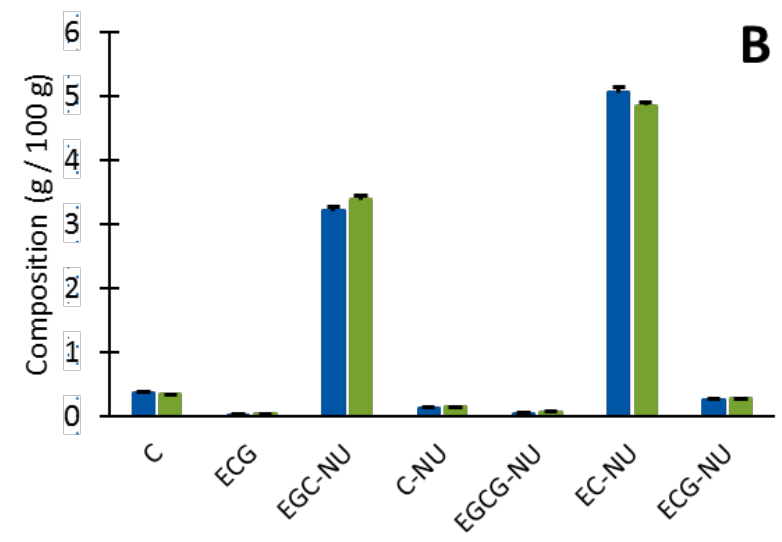

- Menthofuran method $n$ 2-Mercaptoethanol method 
TABLE OF CONTENTS GRAPHICS

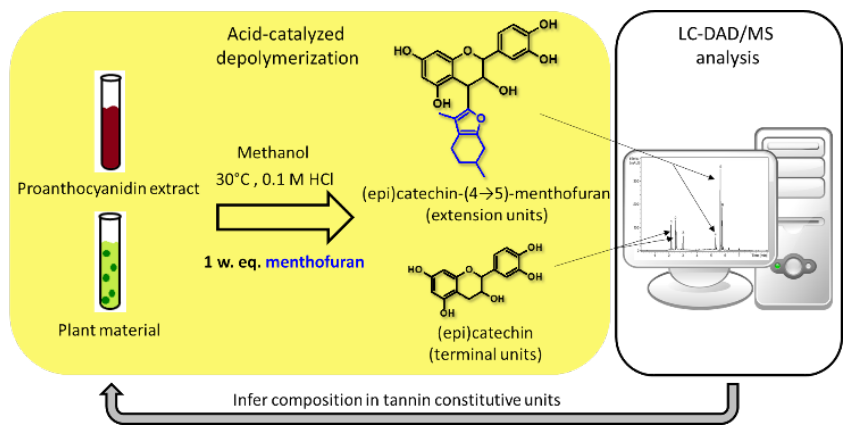

For table of contents only. 